\title{
The costs of traumatic brain injury: a literature review
}

This article was published in the following Dove Press journal:

ClinicoEconomics and Outcomes Research

25 June 2013

Number of times this article has been viewed

\author{
Ioan Humphreys' \\ Rodger L Wood ${ }^{2}$ \\ Ceri J Phillips' \\ Steven Macey ${ }^{3}$ \\ 'Swansea Centre for Health \\ Economics, College of Human \\ and Health Sciences, Swansea \\ University, Wales, UK; ${ }^{2}$ Department \\ of Psychology, College of Human and \\ Health Sciences, Swansea University, \\ Wales, UK; ${ }^{3}$ School of Medicine, \\ Swansea University, Wales, UK
}

Objective: The purpose of this study was to review the literature relating to the psychosocial costs associated with traumatic brain injury (TBI).

Methods: Nine online journal databases, including MEDLINE, CINAHL, PsychINFO, and PUBMED, were queried for studies between July 2010 and May 2012 pertaining to the economic burden of head injuries. Additional studies were identified through searching bibliographies of related publications and using Google internet search engine.

Results: One hundred and eight potentially relevant abstracts were identified from the journal databases. Ten papers were chosen for discussion in this review. All but two of the chosen papers were US studies. The studies included a cost-benefit analysis of the implementation of treatment guidelines from the US brain trauma foundation and a cost-effectiveness analysis of post-acute traumatic brain injury rehabilitation.

Conclusion: Very little research has been published on the economic burden that mild and moderate traumatic brain injury patients pose to their families, careers, and society as a whole. Further research is needed to estimate the economic burden of these patients on healthcare providers and social services and how this can impact current health policies and practices.

Keywords: head trauma, post concussional syndrome, traumatic brain injury (TBI), costs, burden, economics

\section{Introduction}

Traumatic brain injury (TBI) is a major cause of long-term disability in industrialized and developing countries across the world. ${ }^{1}$ An estimated 10 million people will be affected annually by TBI, and by the year 2020, it will surpass many diseases as the major cause of death and disability. This makes TBI a pressing public health and medical problem. An incidence rate of between $150-170$ per 100,000 is demonstrated in Latin America and sub-Saharan Africa due to road traffic accidents compared to a global rate of 106 per 100,000. ${ }^{1}$ The World Health Organization has predicted that road accidents alone, which account for many instances of TBI, will constitute the third largest contributor to the global burden of disease and disability (after heart disease and depression). ${ }^{2}$

A recent study of nearly 3000 serious head trauma cases found that $52 \%$ of survivors (154/100,000 population) were moderate to severely disabled at 1-year. ${ }^{2}$ Many patients never recover full social independence, even though they may have no physical disabilities and a normal life expectancy. At 4 years post injury, Jacobs ${ }^{3}$ found that most survivors lived with their families and neither worked nor attended school, imposing significant psychological burden on families who care for injured relatives. ${ }^{4}$
Correspondence: loan Humphreys Swansea Centre for Health Economics, College of Human and Health Sciences, Swansea University, Singleton Park, Swansea SA2 8PP, Wales, UK

Tel +44 1792602049

Fax +44 1792295643

Email i.humphreys@swansea.ac.uk 
Close relationships are at risk and many marriages and partnerships break down, ${ }^{5}$ increasing the risk of social isolation and subsequent psychological distress to the survivor. Mood disorders are very common during this period and there is a high risk of suicide. ${ }^{6}$ There is little evidence of improvement in psychological problems between 2 and 7 years post injury, ${ }^{7}$ with survivors remaining largely dependent upon family support, thereby potentially imposing a lifetime burden on relatives. ${ }^{8}$

In terms of long term outcomes and recovery, it has been recognized that disturbances of cognition (often in the form of executive dysfunction), mood, and behavior constitute the most debilitating aspects of brain injury. ${ }^{9-11}$ The term neurobehavioral disability ${ }^{12}$ has been employed to encompass the diverse range of disabilities that often result in wholesale changes in a person's character or personality. These changes in personality are often reported by family members as constituting the greatest source of stress and burden, which has an impact on psychosocial outcome. . $^{13,14}$

A range of factors can reflect psychosocial outcomes, such as employment status, social functioning, activities of daily living, financial status, cognitive impairment, and emotional disorders. However, the limited number of measures used by some studies and the variation in measures of outcomes restricts understanding of the socioeconomic impact of TBI. Concepts of functional outcome are based on three dimensions; (1) the need for assistance with selfcare; (2) employment or productivity; and (3) social relationships. To some extent, this is reflected in the International Classification of Impairments, Disabilities, and Handicaps (ICIDH-2) model of social functioning and disability ${ }^{15}$ which redefines disability and handicap as "activities" and "participation". "Activities" are defined as the execution of a task or action by the individual. "Participation" is the nature and extent of a person's involvement in life, covering such areas as communication; mobility; selfcare; domestic life; interpersonal interactions and relationships; and community, civic, and social life. Therefore, to properly evaluate outcome, a variety of measures need to be used, which has not been the case in the majority of outcome studies. The purpose of this study therefore is to review the existing evidence relating to the costs of TBI, particularly the costs relating to psychosocial costs associated with TBI.

Few studies have been conducted on the very long term psychosocial outcome ( $>10$ years post injury) of TBI. Hoofien et $\mathrm{al}^{16}$ reported cases in Israel, ranging from 10-20 years post injury (average 14.1 years). A comprehensive range of outcome measures in this study included psychiatric symptoms, vocational status, family integration, social functioning, and independence in daily routines. Many participants were found to be depressed and lonely with a high burden placed on relatives. The divorce rate was higher than the national average, possibly related to high levels of hostility and temper outbursts displayed by the sample. However, employment rates were relatively high (60\%) and $79 \%$ were living with a spouse or independently. The authors caution that cultural factors may have influenced their data but there was a fairly clear relationship between the presence of behavior problems and poor psychosocial outcome at 14 years. The longitudinal research conducted by Thomsen ${ }^{17,18}$ on a group of 40 very seriously injured cases (post traumatic amnesia $>1$ month) analyzed at 2.5, 10, and 15 years found that psychosocial sequelae of brain injury, such as personality change and emotional problems, were more socially debilitating than physical disability, increasing the risks of social isolation, caregiver stress, and unemployment. These problems persisted for a number of years after follow up, but at the 10-15 year follow up there was an improvement in some of the cases. In the final follow-up, 20 years post injury, 31 patients were seen, nearly half of whom were still living alone, four (12.5\%) were married, four continued to live with parents, and eight $(25.8 \%)$ were in a nursing home. Of the sample, $32 \%$ displayed threatening aggressive or sexual behavior, and $61 \%$ had no social contacts. However, $23 \%$ of respondents had good or very good psychosocial outcomes. Thomsen did not make explicit the basis upon which these judgments of good psychosocial outcome were made but noted that the range of individual differences could not be explained by severity of injury as measured by post traumatic amnesia because cases with the longest post traumatic amnesia seemed to have the best outcomes. Finally, Wood and Rutterford's 2007 UK study also found good long term psychosocial adjustment in a 16 year follow up study, ${ }^{19}$ suggesting that with the passage of time, many individuals settle into a social routine commensurate with what they perceive as a reasonable quality of life.

\section{Methods}

Electronic databases including MEDLINE, CINAHL, PsychINFO, and PUBMED were queried for studies on the economic burden of TBI between July 2010 and May 2012. Additional studies were identified through searching bibliographies of related publications and using the Google internet search engine. Search terms were separated into four distinct topic areas: (1) Head trauma; head trauma, minor head trauma, moderate head trauma, serious head 
trauma, post concussional syndrome, TBI; (2) Personality factors; anxiety sensitivity, alexithymia; (3) Somatoform disorders; hypochondriasis, body dysmorphic disorder; and

(4) Costs; costs associated with, burden of, and economics of, Quality Adjusted Life Years (QALY)s.

\section{Inclusion criteria}

Inclusion criteria for this study included:

- language of publication restricted to English;

- studies relating to the economic burden of head trauma from the health services and/or society's perspective;

- studies published in peer-reviewed journals.

\section{Exclusion criteria}

Exclusion criteria for this study included:

- non English language publications;

- studies concentrating solely on the quality of life of the patients and families without any costs;

- abstracts presented at conferences;

- editorials;

- studies not available in full text.

Ninety-nine potentially relevant abstracts where found from the initial search of the journal databases. A further nine abstracts were included in the initial search from cross referencing the papers found. The hundred and eight abstracts were assessed and analyzed by two of the authors and, after discussions, mutual agreement decided which ones should be included.

Twenty-six abstracts were immediately excluded as per the inclusion criteria (these included one Chinese paper, three duplicates, and two editorials). The remaining 80 abstracts were analyzed for relevance, with 72 of these excluded as they concentrated on the quality of life of the patients and family burden, etc, but didn't discuss costs or the economic burden of TBI. Further, none of the papers specifically discussed post concussional syndrome or personality factors, and the economic burden they can potentially cause. Ten papers were chosen for discussion in the review (see Table 1).

\section{Results}

All but two of the ten papers chosen were US studies, reflecting the relative paucity of research published to date on the economic burden imposed by mild and moderate TBI on families and the careers of survivors, and society as a whole. As most of the studies included were US-based, caution has to be borne in mind when translating the findings to other healthcare systems. To aid cross-analysis the following studies have been placed into relevant sections.

\section{Injury prevention}

Runge $^{20}$ evaluated past research of the cost of injury to US health programs, the government, the private sector, individuals, and at a societal level. The costs associated with injury were classified into injury type, such as head and spinal cord injuries, motor vehicles, firearms, falls, and other causes. Head injuries accounted for $13 \%$ of all hospitalized injuries, $70 \%$ of which were minor head injuries. It estimated the annual cost of all head injuries in the US at nearly \$200 million (1991 dollars). Working from 1985 data, the report stated that $70 \%$ of care was paid for by private sources other than health insurance, federal sources, or workman's compensation. The authors concluded that costs of medical care were rising and that the control of these rising costs should be through injury prevention.

\section{Costs of TBI}

McGregor et al's review ${ }^{21}$ aimed to evaluate the economic importance and efficiency of rehabilitation programs for TBI patients. Their review estimated that the costs per case were between $\$ 33,284$ to $\$ 35,954$ for mild and $\$ 25,174$ to $\$ 81,153$ for moderate TBI. These costs are mostly based on acute care.

Ashley et al's 1997 study ${ }^{22}$ examined the cost effectiveness of post acute TBI rehabilitation using total lifetime savings compared to the net present value for the case of "Mr M". Total lifetime savings quantified the "total dollars saved as a result of the decrease in living costs following rehabilitation when compared to living costs before rehabilitation". The number of "projected remaining life years" were multiplied by these annual savings to produce a total lifetime savings. Net present value determines the present value of the costs and benefits of post-acute TBI, comparing four cost projections of rehabilitation. The programs were annual life care cost without rehabilitation, projected postacute rehabilitation program cost, annual life care cost with supervised home placement, and annual life care cost with behavioral group home placement. The cost (1991 dollars) of care and treatment for the different options were: annual life care cost without rehabilitation, $\$ 222,600$; projected post-acute rehabilitation program cost, $\$ 450,000$; annual life care cost with supervised home placement, $\$ 49,688$; and annual life care cost with behavioral group home placement, $\$ 84,082$.

A 2002 study by Schulman et $\mathrm{al}^{23}$ estimated the direct and indirect cost burden associated with nonuniversal use of bicycle helmets in the 50 states of the US. The study analyzed the emergency department records from the National Center 
for Health Statistics (NCHS) using 1993-1995 data. Indirect costs were calculated using the human capital approach. Productivity loss due to partial disability was not calculated. However, loss of productivity for children and adolescents not yet working was calculated and the authors concluded that some 327 fatal, 6900 hospitalized, and 100,000 emergency department cases could have been avoided by universal use of bicycle helmets. The authors estimated this to equate to $\$ 81$ million in direct healthcare costs and $\$ 2.3$ billion in indirect healthcare costs. Additionally, these costs vary state to state, depending on population size, with California having an estimate of direct and indirect costs of $\$ 320$ million per annum.

Faul et al's 2007 cost-benefit analysis ${ }^{24}$ estimated the financial implications of implementing the treatment guidelines of the Brain Trauma Foundation for severe TBI patients. Using published data, the authors estimated that the implementation of the Brain Trauma Foundation treatment would have a positive impact on longterm neurologic disability burden to family, work, and society as a whole. The medical savings were estimated to be $\$ 11,280$ per patient compared to the estimated cost to society of $\$ 164,951$. They estimated the total societal cost savings to be $\$ 3,837,577,538$.

A 2009 Missouri study ${ }^{25}$ considered the health and economic burden of death from TBI between 2001 and 2005. The four main causes of death from TBI were motor vehicle accidents, firearms, unintentional falls, and motorcycle crashes. There was no classification of the severity (eg, mild, moderate, etc) of injury. The authors estimated the social cost in terms of years of potential life lost as well as indirect costs (ie, lost productivity) using present discounted value of future earnings discounted at 3\% per annum. Additionally, direct costs were calculated from emergency department records. The authors calculated that the total productivity lost due to TBI related deaths was almost $\$ 1.1$ billion annually with the rate three times higher for males than females. The highest productivity cost losses were due to motor vehicle crashes at $\$ 513$ million. Limitations of the study were underestimating the emergency department visits and hospitalization costs (direct costs), due to underestimation of TBI incidence and the omission of costs due to lost wages, disability, drugs, and disability. The authors concluded that the indirect costs are higher than the direct costs, but this study only quantified the costs due to mortality and not the cost burden of survivors, their families, or their careers.

Rockhill et al's 2010 study $^{26}$ examined the associated healthcare costs of mild TBI and psychological distress in children and adolescents. Using existing Health Maintenance Organisation
(HMO) mental health data the study comprised 489 individuals and looked at the extent of healthcare utilization 3 years post TBI. Over $36 \%$ of the total healthcare costs for the TBI exposed individuals were incurred in the first 6 months after injury and nearly $53 \%$ were incurred in the first year. For patients suffering psychological distress, approximately $24 \%$ of the total 3 -year costs occurred in the first 3 months and $41 \%$ occurred in the first year. The authors concluded that both mild TBI and psychological distress were linked to higher total healthcare costs in the 3 years following an accident in children under 15 years. The 3-year incremental cost associated with psychological distress in a TBI patient was estimated to be $\$ 3529$ compared to the incremental cost associated with psychological distress in a nonTBI patient of \$2769. However, the authors only calculated direct medical costs and did not include out of pocket expenses and indirect costs linked to loss of time or income incurred by the children or their families.

\section{Cost-effectiveness of rehabilitation}

A 1999 UK study by Wood et $\mathrm{al}^{27}$ aimed to examine community based social and behavioral rehabilitation and its ability to reduce social dependency in a group of adults with neurobehavioral disability after brain injury. The study also aimed to evaluate the effect rehabilitation had on direct costs associated with the community support needed by the cohort before and after rehabilitation. The study cohort comprised 76 people with severe brain injury receiving post-acute social and behavioral rehabilitation at two centers operated by the UK Brain Injury Rehabilitation Trust. The measures employed by the study tried to reflect: the level of social recovery; employment; persistent neurobehavioral problems; care support; costs of care; and factors affecting outcome. The authors have adopted a narrow economic perspective by just looking at the direct costs associated with the community support, therefore the study doesn't follow established guidelines for cost-effectiveness studies and caution should be used when looking at the results. The authors conclude that time between injury and the start of rehabilitation is an influencing factor. For those receiving treatment within 2 years post injury, the cost effectiveness of rehabilitation appears to be greatest. However, significant social outcomes and savings on care were also estimated for those in the cohort who received rehabilitation at later stages.

A 2003 study $^{28}$ aimed to quantify the longterm costs and employment characteristics for people with moderate to severe TBI in supported employment schemes over a 14-year period. This longitudinal study examined 59 individuals who had been placed in at least one supported employment 
model between 1985 and 1999. The study found that the average gross earnings were $\$ 26,130$ (ranging from $\$ 571$ to $\$ 168,291)$. Annual costs of supported employment services were $\$ 8614$ which meant that the average earnings were $\$ 17,515$ greater than the cost of the employment services. The authors concluded that supported employment services appeared to be cost-effective, but also noted that, for example, start up costs associated with supported employment were not considered, as the individuals in this study had already been enrolled in the services. The authors suggested that emerging programs should expect higher costs in the initial stages of set up, while additional costs of assistive devices or accommodations to enable job placement were not included. Further, additional services such as physiotherapists, speech therapists, and other rehabilitation professionals were not calculated. The authors concluded that additional research is needed to examine the intangible benefits as well as the impact on social service and disability insurance costs.

Worthington et al's 2006 UK study $^{29}$ expands on the methodology employed by Wood et $\mathrm{al}^{27}$ by looking at a clinical and cost outcome evaluation of a post-acute neurobehavioral rehabilitation program. A cohort of 101 participants with severe brain injury was recruited for the study. Key dependent measures of outcome were chosen: accommodation; support; independent living ability; occupation; social roles; and costs. Again, along with Wood et al study, the costs collected were only direct costs, so the authors adopt a similarly narrow economic perspective. The authors observed that patients admitted within 1-year of injury made the most progress. However, improvements were seen in the entire cohort, regardless of time since injury. Sensitivity analysis showed projected lifetime savings of between $£ 1.1 \mathrm{~m}$ and $£ 800,000$ for patients admitted 12 months post injury; savings of between $£ 700,000$ and $£ 500,000$ within 2 years post injury; and savings of between $£ 500,000$ and $£ 360,000$ for admission after 2 years. The authors conclude that initial costs associated with rehabilitation appeared to be generally offset by savings in costs of support in the medium and longterm.

Finally, a recent interrogation of the emergency department data from the All Wales Injury Surveillance System

Table I Traumatic brain injury studies

\begin{tabular}{|c|c|c|c|c|c|c|c|c|}
\hline & Date & Country & $\%$ Female & $\begin{array}{l}\text { Mean } \\
\text { age }\end{array}$ & TBI & $\begin{array}{l}\text { Study } \\
\text { design }\end{array}$ & $\begin{array}{l}\text { Study design } \\
\text { grouping }\end{array}$ & $\begin{array}{l}\text { Estimated annual costs } \\
\text { (2009 conversion) }\end{array}$ \\
\hline Runge JW'I & 1993 & US & $\mathrm{N} / \mathrm{A}$ & $\mathrm{N} / \mathrm{A}$ & $\begin{array}{l}\text { Severe, } \\
\text { moderate, mild }\end{array}$ & Review & $\begin{array}{l}\text { Injury } \\
\text { prevention }\end{array}$ & $\$ 302$ million \\
\hline $\begin{array}{l}\text { McGregor K, } \\
\text { et } \mathrm{al}^{22}\end{array}$ & 1997 & US & $\mathrm{N} / \mathrm{A}$ & N/A & Moderate, mild & Review & Costs of TBI & $\begin{array}{l}\text { Direct costs range from } £ 28,300 \\
\text { (mild) to } £ 59,600 \text { (moderate) } \\
\text { per patient }\end{array}$ \\
\hline $\begin{array}{l}\text { Ashley MJ, } \\
\text { et } \mathrm{al}^{23}\end{array}$ & 1997 & US & N/A & 33 & Severe & $\begin{array}{l}\text { Cost } \\
\text { effectiveness } \\
\text { analysis }\end{array}$ & Costs of TBI & $\begin{array}{l}\text { Direct costs range from } \$ 67,504 \\
\text { to } \$ 1 \mid 4,23 I \text { per patient }\end{array}$ \\
\hline $\begin{array}{l}\text { Wood RL, } \\
\text { et } \mathrm{al}^{28}\end{array}$ & 1999 & UK & 25 & 27 & Mix & $\begin{array}{l}\text { Cost } \\
\text { effectiveness } \\
\text { analysis }\end{array}$ & $\begin{array}{l}\text { Cost } \\
\text { effectiveness } \\
\text { of rehabilitation }\end{array}$ & $\begin{array}{l}\text { Estimated follow up costs: } 0-2 \text { years } \\
\text { post injury } £ 1,260,000 ; 2-5 \text { years } \\
\text { post injury } £ 1,610,000 \text { and more } \\
\text { than } 5 \text { years post injury } £ 2,020,000\end{array}$ \\
\hline $\begin{array}{l}\text { Schulman J, } \\
\text { et } \mathrm{al}^{24}\end{array}$ & 2002 & US & $\mathrm{N} / \mathrm{A}$ & N/A & $\begin{array}{l}\text { Severe, } \\
\text { moderate, mild }\end{array}$ & $\begin{array}{l}\text { Cost of } \\
\text { injury }\end{array}$ & Costs of TBI & $\begin{array}{l}\text { Direct costs }=\$ 98 \text { million. Indirect } \\
\text { costs }=\$ 2.8 \text { billion }\end{array}$ \\
\hline $\begin{array}{l}\text { Wehman P, } \\
\text { et } \mathrm{al}^{29}\end{array}$ & 2003 & US & 18.6 & 32.6 & $\begin{array}{l}\text { Moderate, } \\
\text { severe }\end{array}$ & $\begin{array}{l}\text { Cost of } \\
\text { injury }\end{array}$ & $\begin{array}{l}\text { Cost } \\
\text { effectiveness } \\
\text { of rehabilitation }\end{array}$ & - \\
\hline $\begin{array}{l}\text { Worthington } \\
A D \text {, et } \mathrm{al}^{30}\end{array}$ & 2006 & UK & N/A & 35.6 & - & $\begin{array}{l}\text { Cost benefit } \\
\text { analysis }\end{array}$ & $\begin{array}{l}\text { Cost } \\
\text { effectiveness } \\
\text { of rehabilitation }\end{array}$ & $\begin{array}{l}\text { Estimated lifetime savings } \\
£ 863,000-£ 1.190,000 \text { admitted } \\
\text { within } 12 \text { months of injury, } \\
£ 539,000-£ 755,000 \text { within } 2 \text { years } \\
\text { of injury and } £ 388,000-£ 539,000 \text { for } \\
\text { admissions after } 2 \text { years }\end{array}$ \\
\hline Faul M, et $\mathrm{al}^{25}$ & 2007 & US & N/A & N/A & Severe & $\begin{array}{l}\text { Cost benefit } \\
\text { analysis }\end{array}$ & Costs of TBI & Cost savings of approx $\$ 4.2$ billion \\
\hline $\begin{array}{l}\text { Kayani NA, } \\
\text { et } \mathrm{al}^{26}\end{array}$ & 2009 & US & $N / A$ & N/A & - & $\begin{array}{l}\text { Cost of } \\
\text { injury }\end{array}$ & Costs of TBI & Productivity loss of $\$ 521$ million \\
\hline $\begin{array}{l}\text { Rockhill CM, } \\
\text { et } \mathrm{al}^{27}\end{array}$ & 2010 & US & 37.8 & $\mathrm{~N} / \mathrm{A}$ & Mild & $\begin{array}{l}\text { Cost of } \\
\text { injury }\end{array}$ & Costs of TBI & - \\
\hline
\end{tabular}

Abbreviations: $\mathrm{TBI}$, traumatic brain injury; N/A, not applicable. 
$(\text { AWISS) })^{30}$ and the inpatient data from the Patient Episode Database for Wales (PEDW) from 01/04/2005 to 31/03/2007 found that, on average, a skull-brain index injury resulted in mean excess direct medical per patient costs of $£ 28$ in the emergency department sector; $£ 241$ in the outpatient sector; and £5,985 in the inpatient sector. The inpatient cost highlighted here indicates the extent of both the direct and indirect costs resulting from TBI.

\section{Discussion}

The studies described herein have been undertaken in an attempt to estimate the economic burden relating to TBI and the psychosocial conditions associated with neurobehavioral disability. These factors can seriously affect the quality of life of patients and their families, as well as increase the economic burden on society as a whole.

The studies included herein all attempt to quantify either the economic burden of TBI, be it mild, moderate or severe, or they attempt to calculate the potential cost savings both to the individual and/or society as a whole through successful TBI rehabilitation programs. For example, Runge et $\mathrm{al}^{20}$ estimated annual direct cost burden of TBI (mild, moderate, and severe) to be $\$ 302$ million (2009 prices), whereas Schulman et $\mathrm{al}^{23}$ estimated the same direct cost burden as $\$ 98$ million or $\$ 2.8$ billion (indirect costs; 2009 prices). Worthington et $\mathrm{al}^{29}$ estimated cost savings of between $£ 863,000$ and $£ 1.190,000$ admitted within 12 months of injury; $£ 539,000-£ 755,000$ admitted within 2 years of injury; and $£ 388,000-£ 539,000$ for admissions after 2 years (2009 prices) for all types of TBI. Faul et al ${ }^{24}$ estimated total cost savings of approximately $\$ 4.2$ billion (2009 prices) for severe TBI.

From the current state of knowledge presented in this selection of papers, it is evident that past research seems inconsistent and prone to differing methodological approaches in terms of the costs and outcomes included in the studies. A number of useful frameworks and matrices have been proposed although all papers have limitations associated with them. For example, Ashley et al's 1997 study $^{22}$ compared four cost projections of rehabilitation and calculates the net present value at 35 years discounted at $4 \%$ per annum for each of the programs. However, the authors don't specifically estimate the out of pocket and indirect costs incurred by "Mr M" and his family post TBI. Further, Faul et al's 2007 cost-benefit analysis study ${ }^{24}$ estimated the financial implications of implementing the treatment guidelines of the Brain Trauma Foundation, but only studied severe
TBI patients and failed to estimate mild or moderate TBI. Finally, Worthington et al's 2006 study $^{29}$ (a methodological update of Wood et al's 1999 study $^{27}$ ) aimed to carry out a cost-benefits analysis of social outcomes from neurobehavioral rehabilitation programs. The methodology employed in this study has the potential to yield important economic results, but the perspective adopted (only direct costs collected) needs to be widened to enable the full societal impact of neurobehavioral rehabilitation to be analyzed.

\section{Conclusion}

As presented in the literature reviewed above, the assessment of the economic burden of traumatic brain injury is relatively new, and is subject to numerous attempts at quantification through varying methods. However, the potential cost savings both to the individual and/or society as a whole through successful TBI rehabilitation programs is substantial.

The evaluation of traumatic head injury rehabilitation treatment, and the possible consequential post treatment economic burden, provides an excellent scenario for illustrating the complexities involved in attempting to integrate the evidence relating to rehabilitation effectiveness and resource utilization. However, the apparent lack of recent and substantial evidence to support this review may also present itself as a limitation to the study. Therefore, further cost analysis research is needed to estimate the economic burden of these patients on the National Health Service (NHS) and social services within the UK. Thus, evidence is welcomed and needed to prove whether this can have an impact on current public health policies. A recent study by Feigin, ${ }^{32}$ a large epidemiological study of TBI in New Zealand, has contributed to filling the knowledge gap on TBI incidence and severity. To improve health outcomes, however, public health practice must translate such findings into policies and intervention strategies. It advertised itself as "the largest and most recent study to identify and quantify the potential economic burden of TBI". In a broader context, the value of the aforementioned study lies in advocating for new research and development of projects and activities that will reduce the incidence of TBI.

The present review could potentially contribute substantially to stimulation of public interest and allocation of both public and private resources to support research and development in this field.

\section{Disclosure}

The authors report no conflicts of interest in this work. 


\section{References}

1. Hyder AA, Wunderlich CA, Puvanachandra P, Gururaj G, Kobusingye OC. The impact of traumatic brain injuries: a global perspective. NeuroRehabilitation. 2007;22(5):341-353.

2. Thornhill S, Teasdale GM, Murray GD, McEwen J, Roy CW, Penny KI. Disability in young people and adults one year after head injury: prospective cohort study. BMJ. 2000;320(7250):1631-1635.

3. Jacobs HE. The Los Angeles Head Injury Survey: procedures and initial findings. Arch Phys Med Rehabil. 1988;69(6):425-431.

4. Brooks N, Campsie L, Symington C, Beattie A, McKinlay W. The five year outcome of severe blunt head injury: a relative's view. J Neurol Neurosurg Psychiatr. 1986;49(7):764-770.

5. Wood RL, Yurdakul LK. Change in relationship status following traumatic brain injury. Brain Inj. 1997;11(7):491-501.

6. Fleminger S, Oliver DL, Williams WH, Evans J(2003). The neuropsychiatry of depression after brain injury. Neuropsychol Rehabil. 13(1-2):65-87.

7. Oddy M, Coughlan T, Tyerman A, Jenkins D. Social adjustment after closed head injury: a further follow-up seven years after injury. J Neurol Neurosurg Psychiatr. 1985;48(6):564-568.

8. Willer BS, Allen KM, Liss M, Zicht MS. Problems and coping strategies of individuals with traumatic brain injury and their spouses. Arch Phys Med Rehabil. 1991;72(7):460-464.

9. Murray CJ, Lopez AD. Alternative projections of mortality and disability by cause 1990-2020: Global Burden of Disease Study. Lancet. 1997;349(9064):1498-1504.

10. Brooks N, McKinlay W, Symington C, Beattie A, Campsie L. Return to work within the first seven years of severe head injury. Brain Inj. 1987;1(1):5-19.

11. Tate RL. Issues in the management of behaviour disturbance as a consequence of severe head injury. Scand J Rehabil Med. 1987;19(1): 13-18.

12. Wood RL. Understanding neurobehavioural disability. In: Wood RL, McMillan TM, editors. Neurobehavioural Disability and Social Handicap following Traumatic Brain Injury. Hove: Psychology Press; 2001:1-28.

13. Lezak MD. Living with the characterologically altered brain injured patient. J Clin Psychiatry. 1978;39(7):592-598.

14. Brooks DN, McKinlay W. Personality and behavioural change after severe blunt head injury - a relative's view. J Neurol Neurosurg Psychiatr. 1983;46(4):336-344.

15. www.who.int [homepage on the Internet]. The International Classification of Functioning (ICF), Disability and Health. World Health Organization; 2001. Available from: http://www.who.int/classifications/ icf/en/. Accessed May 4, 2013.

16. Hoofien D, Gilboa A, Vakil E, Donovick PJ. Traumatic brain injury (TBI) 10-20 years later: a comprehensive outcome study of psychiatric symptomatology, cognitive abilities and psychosocial functioning. Brain Inj. 2001;15(3):189-209.

17. Thomsen IV. The patient with severe head injury and his family. A follow-up study of 50 patients. Scand J Rehabil Med. 1974;6(4): $180-183$.
18. Thomsen IV. Late outcome of very severe blunt head trauma: a 10-15 year second follow-up. J Neurol Neurosurg Psychiatr. 1984;47(3):260-268.

19. Thomsen IV. Late psychosocial outcome in severe traumatic brain injury.

20. Wood RL, Rutterford NA. Long-term effect of head trauma on intellectual abilities: a 16-year outcome study. J Neurol Neurosurg Psychiatr. 2006;77(10):1180-1184.

21. Runge JW. The cost of injury. Emerg Med Clin North Am. 1993;11(1): 241-253.

22. McGregor K, Pentland B. Head injury rehabilitation in the UK: an economic perspective. Soc Sci Med. 1997;45(2):295-303.

23. Ashley MJ, Schultz JD, Bryan VL, Krych DK, Hays DR. Justification of postacute traumatic brain injury rehabilitation using net present value techniques: a case study. 1997;1(5):33-41.

24. Schulman J, Sacks J, Provenzano G. State level estimates of the incidence and economic burden of head injuries stemming from non-universal use of bicycle helmets. Inj Prev. 2002;8(1):47-52.

25. Faul M, Wald MM, Rutland-Brown W, Sullivent EE, Sattin RW. Using a cost-benefit analysis to estimate outcomes of a clinical treatment guideline: testing the Brain Trauma Foundation guidelines for the treatment of severe traumatic brain injury. J Trauma. 2007;63(6):1271-1278.

26. Kayani NA, Homan S, Yun S, Zhu BP. Health and economic burden of traumatic brain injury: Missouri, 2001-2005. Public Health Rep. 124(4):551-560.

27. Rockhill CM, Fann JR, Fan MY, Hollingworth W, Katon WJ. Healthcare costs associated with mild traumatic brain injury and psychological distress in children and adolescents. Brain Inj. 2010;24(9):1051-1060.

28. Wood RL, McCrea JD, Wood LM, Merriman RN. Clinical and cost effectiveness of post-acute neurobehavioural rehabilitation. Brain Inj. 1999;13(2):69-88.

29. Wehman P, Kregel J, Keyser-Marcus L, et al. Supported employment for persons with traumatic brain injury: a preliminary investigation of long-term follow-up costs and program efficiency. Arch Phys Med Rehabil. 2003;84(2):192-196.

30. Worthington AD, Matthews S, Melia Y, Oddy M. Cost-benefits associated with social outcome from neurobehavioural rehabilitation. Brain Inj. 2006;20(9):947-957.

31. www.capic.org.uk. [homepage on the Internet]. Accident and Emergency Department Data - All Wales Injury Surveillance Systems (AWISS). Collaboration for Accident Prevention and Injury Control; Year. Available from: http://www.capic.org.uk/aande.html. Accessed May 4, 2013.

32. Feigin VL, Theadom A, Barker-Collo S, Starkey NJ et al. Incidence of traumatic brain injury in New Zealand: a population-based study. Lancet Neurol. 2013;12(1):53-64.
ClinicoEconomics and Outcomes Research

\section{Publish your work in this journal}

ClinicoEconomics \& Outcomes Research is an international, peerreviewed open-access journal focusing on Health Technology Assessment, Pharmacoeconomics and Outcomes Research in the areas of diagnosis, medical devices, and clinical, surgical and pharmacological intervention. The economic impact of health policy and health systems

\section{Dovepress}

organization also constitute important areas of coverage. The manuscript management system is completely online and includes a very quick and fair peer-review system, which is all easy to use. Visit http://www.dovepress.com/testimonials.php to read real quotes from published authors. 